Biochemical Pharmacology, Vol. 16, pp. 2047-2049. Pergamon Press Ltd. 1967. Printed in Great Britain

\title{
The protective effect of nicotinamide on carbon tetrachloride-induced hepatotoxicity*
}

(Received 9 January 1967; accepted 28 March 1967)

THE CHANGE in hepatic pyridine nucleotide levels which results as a consequence of carbon tetrachloride $\left(\mathrm{CCl}_{4}\right)$ administration has been implicated as a factor in its hepatotoxicity. ${ }^{1-3}$ Gallagher et al..$^{4-6}$ found that the administration of either nicotinic acid or tryptophan protected rats and sheep to a considerable extent against the lethal effects of large doses of $\mathrm{CCl}_{4}$. The injection of nicotinamide into normal mice resulted in large increases in the level of nicotinamide adenine dinucleotide (NAD) in liver and other tissues. ${ }^{7}$ It was shown in preliminary studies in our laboratory that, al though $\mathrm{CCl}_{4}$ or nicotinamide (NA) when administered alone to rats did not alter the body temperature, the combined effect of these two agents resulted in a fall in temperature from a control level of $36.8^{\circ}$ $(n=18)$ to $33 \cdot 5^{\circ}(n=10)$. Because it had been shown that the liver damage observed after $\mathrm{CCl}_{4}$ may be prevented, at least in part, by reducing the body temperature, ${ }^{8}$ the protective effects of nicotinamide against $\mathrm{CCl}_{4}$ were reinvestigated. The data indicate that the protection afforded by nicotinamide is not contingent upon a fall in body temperature.

\section{MATERIALS AND METHODS}

Female albino Sprague-Dawley or Holtzmann rats weighing from 180 to $220 \mathrm{~g}$ were used throughout the investigation. Animals were sacrificed by decapitation or by exsanguination after excision of the liver under light hexobarbital administration.

A $1: 1$ mixture of $\mathrm{CCl}_{4}$ and peanut oil $(2.5 \mathrm{ml} \mathrm{CCl} 4 / \mathrm{kg})$ was administered orally by stomach tube. Control animals were injected with an equal amount of peanut oil. Nicotinamide was administered i.p. $23 \mathrm{hr}(500 \mathrm{mg} / \mathrm{kg}), 19 \mathrm{hr}(250 \mathrm{mg} / \mathrm{kg})$, and $12 \mathrm{hr}(500 \mathrm{mg} / \mathrm{kg})$ before sacrifice. Animals were starved $20 \mathrm{hr}$ prior to sacrifice.

The incubator used to maintain the body temperature of the rats consisted of a well ventilated oven maintained at $31^{\circ}$. The rectal temperature of the rats was measured with a Tele-thermometer (Yellow Springs Instrument Co., Ind.).

Tissue pyridine nucleotides were measured by selectively destroying the oxidized or reduced pyridine nucleotides in base or acid, respectively. Both oxidized and reduced forms of the pyridine nucleotides were determined according to the method of Lindall and Lazarow. ${ }^{9}$ The pyridine nucleotide content of mitochondria was measured by the same method after isolation of the mitochondria as described by Brody and Bain. ${ }^{10}$ The protein content of mitochondria was measured by a modification of the method of Gornall et al. ${ }^{11}$ Statistical comparison was based on the Student's $t$-test. Tissues for histologic examination were fixed in buffered $10 \%$ formalin and hematoxylin-eosin stained sections were prepared.

\section{RESULTS AND DISCUSSION}

Oxidized and reduced pyridine nucleotides were measured in whole liver and in liver mitochondria in six groups of rats: (1) control, (2) $\mathrm{CCl}_{4}$-treated, (3) nicotinamide-treated, (4) nicotinamide-treated and incubated, (5) $\mathrm{CCl}_{4-}$ and nicotinamide-treated, and (6) $\mathrm{CCl}_{4-}$ and nicotinamide-treated and incubated. The results of these experiments are shown in Tables 1 and 2. Administration of nicotinamide increased levels of NAD above normal levels. When nicotinamide-treated rats were maintained in the incubator, the levels of NAD and total pyridine nucleotides were dramatically decreased below that of nonincubated rats treated with nicotinamide. Additionally, when $\mathrm{CCl}_{4}$ was given to rats that were also given nicotinamide, the NAD fraction was significantly decreased below the levels in rats that had received only nicotinamide. This was observed whether the rats were incubated at $31^{\circ}$ or left at room temperature.

Similar changes could also be observed in the levels of reduced pyridine nucleotides. Again, administration of nicotinamide to normal rats significantly elevated $\mathrm{NADH}$ levels. Combined $\mathrm{CCl}_{4}$

* Supported by United States Public Health Service Grant GM-04759-C9. 
and nicotinamide treatment decreased NADH levels below that seen in rats given nicotinamide and left at room temperature.

In experiments with liver mitochondria, the pyridine nucleotide levels were affected in a qualitatively similar fashion. The administration of $\mathrm{CCl}_{4}$ alone caused a fall in mitochondrial oxidized and reduced pyridine nucleotides. Nicotinamide administered concurrently with $\mathrm{CCl}_{4}$ maintained the pyridine nucleotides at levels above those seen in rats treated with $\mathrm{CCl}_{4}$ alone.

TABle 1. EFFect of $\mathrm{CCl}_{4}$, Nicotinamide AND ENVIRONMENTAL temperature on REDUCED AND OXIDIZED PYRIDINE NUCLEOTIDES IN THE LIVER*

\begin{tabular}{lccccc}
\hline & N & NADH & NADPH & NAD & NADP \\
\hline Control & 14 & $129 \pm 11$ & $274 \pm 25$ & $367 \pm 23$ & $60 \pm 9$ \\
$\mathrm{CCl}_{4}$ & 7 & $56 \pm 25 \dagger$ & $89 \pm 24 \dagger$ & $177 \pm 49 \dagger$ & $58 \pm 12$ \\
$\mathrm{NA}$ & 7 & $363 \pm 14 \dagger$ & $301 \pm 42$ & $1420 \pm 216 \dagger$ & $182 \pm 69$ \\
$\mathrm{NA}$ (incubated) & 9 & $225 \pm 68$ & $277 \pm 39$ & $720 \pm 184 \ddagger$ & $114 \pm 50$ \\
$\mathrm{CCl}_{4}+\mathrm{NA}$ & 6 & $178 \pm 33 \ddagger$ & $218 \pm 27$ & $624 \pm 63 \ddagger \S$ & $62 \pm 31$ \\
$\mathrm{CCl}_{4}+\mathrm{NA}$ (incubated) & 7 & $160 \pm 36 \ddagger \S$ & $233 \pm 59$ & $589 \pm 45_{\ddagger} \S$ & $101 \pm 34$ \\
\hline
\end{tabular}

$*$ Mean \pm S.E.M. $=\mu \mathrm{g} / \mathrm{g}$ liver, wet weight.

$\dagger$ Significant difference from control, $P<0.05$.

$\ddagger$ Significant difference from NA alone, $\mathrm{P}<0.05$.

$\S$ Significant difference from $\mathrm{CCl}_{4}, \mathrm{P}<0.05$.

Table 2. The efFect of $\mathrm{CCl}_{4}$, Nicotinamide AND ENVIRONMENTAL temperature ON THE CONTENT OF OXIDIZED AND REDUCED PYRIDINE NUCLEOTIDES IN LIVER MITOCHONDRIA*

\begin{tabular}{lccccc}
\hline & N & NADH & NADPH & NAD & NADP \\
\hline Control & 17 & $0.95 \pm 0.06$ & $1.74 \pm 0.13$ & $0.89 \pm 0.06$ & $0.38 \pm 0.02$ \\
$\mathrm{CCl}_{4}$ & 21 & $0.59 \pm 0.06 \dagger$ & $0.75 \pm 0.08 \dagger$ & $0.47 \pm 0.04 \dagger$ & $0.25 \pm 0.04 \dagger$ \\
$\mathrm{CCl}_{4}+\mathrm{NA}$ & 12 & $0.93 \pm 0.14_{\ddagger}^{\ddagger}$ & $0.99 \pm 0.14_{\ddagger}^{\ddagger}$ & $0.68 \pm 0.07 \dagger_{\ddagger}$ & $0.29 \pm 0.03 \dagger$ \\
$\mathrm{CCl}_{4}+\mathrm{NA}$ (incubated) & 12 & $0.97 \pm 0.15 \ddagger$ & $1.38 \pm 0.23 \ddagger$ & $0.67 \pm 0.07 \dagger \ddagger$ & $0.30 \pm 0.06 \dagger$
\end{tabular}

$*$ Mean + S.E.M. $=\mu \mathrm{g} / \mathrm{mg}$ protein.

$\dagger$ Significant difference from normal, $\mathrm{P}<0.05$.

¥ Significant difference from $\mathrm{CCl}_{4}, \mathrm{P}<0.05$.

Hepatic morphological changes supported the biochemical findings reported above. A photomicrograph of normal liver is shown in Fig. 1, section 1. The classical effects of $\mathrm{CCl}_{4}$ are shown in Fig. 1, section 2. Cells have been disrupted and necrotic cellular debris can be seen in the area surrounding the central vein. Lipid accumulation is represented by the fat vacuoles in cells around the central vein. Small fat droplets, indicative of lipid accumulation, are seen in cells which extend peripherally almost as far as the portal triad. Normal cells are observed only in the area of the portal triad. The protective effects of nicotinamide are seen in Fig. 1, section 3. In this typical section of rat liver, the animal received a single dose of nicotinamide prior to the challenging dose of $\mathrm{CCl}_{4}$ and two doses of nicotinamide after the halogenated hydrocarbon. With this treatment, the morphologicapicture is not strikingly different from normal rat liver (cf section 1). Even after incubation the protective effects of the nicotinamide on the liver of the $\mathrm{CCl}_{4}$-treated animal are apparent (Fig. 1, sec. tion 4). 

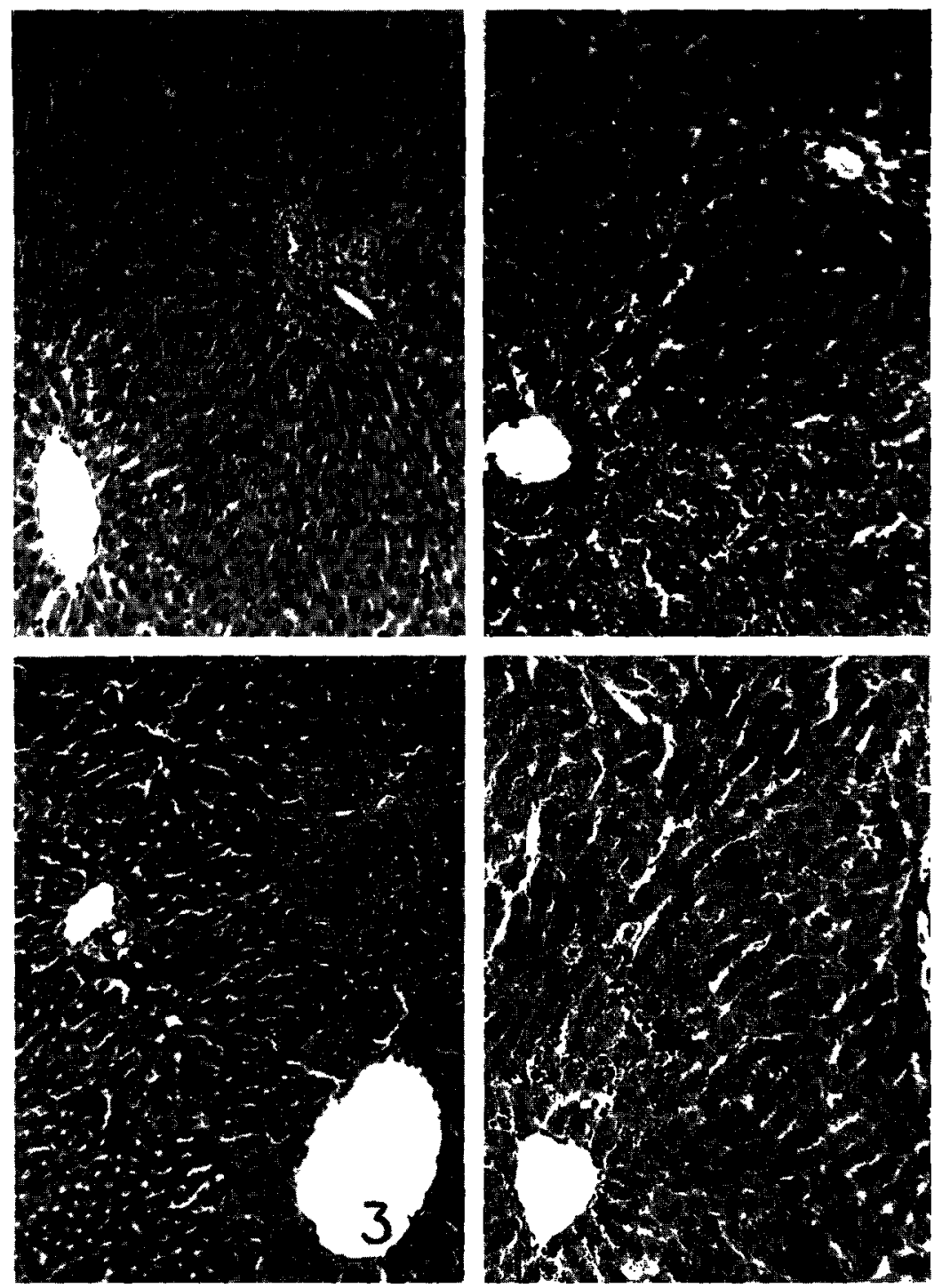

FIG. 1. (1) Liver from a normal rat (H \& E, 150 . ). (2) Liver from rat which received $2.5 \mathrm{ml} / \mathrm{kg}$ $\mathrm{CCl}_{4}$ in peanut oil $20 \mathrm{hr}$ before sacrifice $(\mathrm{H} \mathrm{\&} \mathrm{E}, 150<)$. (3) Liver from rat which received nicotinamide and $2.5 \mathrm{ml} / \mathrm{kg} \mathrm{CCl}$. The rat was sacrificed $20 \mathrm{hr}$ after the administration of $\mathrm{CCl}_{4}$ ( $\mathrm{H} \& \mathrm{E}, 150$, ). (4) Liver from rat which received nicotinamide and $\mathrm{CCl}_{4}$. The normal temperature was maintained by placing the rat in an incubator. The rat was sacrificed $20 \mathrm{hr}$ after receiving $\mathrm{CCI}_{\downarrow}(\mathrm{H} \& \mathrm{~F}, 150 \%)$. 
Thus it is evident from these data that the protection afforded by nicotinamide against $\mathrm{CCl}_{4}$ damage is not dependent on the fall in body temperature that is normally seen after nicotinamide and $\mathrm{CCl}_{4}$ administration. In the present studies nicotinamide given to rats in large doses prior to $\mathrm{CCl}_{4}$ afforded a dramatic protection. This protection by nicotinamide was reflected in the levels of pyridine nucleotides both in the whole liver and in the mitochondria as well as in the histological studies. These data compare favorably with those of Gallagher et al., ${ }^{4-6}$ who reported that other precursors of pyridine nucleotides (nicotinic acid and tryptophan)wrotected rats to a considerable extent against the lethal effects of large doses of $\mathrm{CCl}_{4}$.

The concurrent administration of $\mathrm{CCl}_{4}$ and nicotinamide caused a marked hypothermia, but neither nicotinamide nor $\mathrm{CCl}_{4}$ alone caused any change in normal body temperature. It is especially noteworthy that an increase in the environmental temperature in animals given nicotinamide alone, caused a dramatic fall in pyridine nucleotides.

The recent observations reported by Slater et al. ${ }^{12}$ are pertinent to the role of pyridine nucleotides in the liver damage caused by $\mathrm{CCl}_{4}$. These workers found that there was no significant change in the concentration of oxidized pyridine nucleotides at $1 / 2,1,2,3,5$, and $18 \mathrm{hr}$ after $\mathrm{CCl}_{4}$. They found, however, that NADPH was significantly decreased $30 \mathrm{~min}$ after $\mathrm{CCl}_{4}$ administration. Preliminary observations in our laboratory support these data of Slater $e t$ al. They concluded that NADP and $\mathrm{NADPH}$ concentrations are related to the necrogenic chain of events that occur after $\mathrm{CCl}_{4}$ administration. More recent reports by Slater et al..$^{13}$ have revealed that promethazine, cetyltrimethylammonium bromide, and nupercaine, which substantially delay the appearance of centrilobular necrosis, also minimized the loss of liver pyridine nucleotides that normally occurs $1 \mathrm{hr}$ after administration of $\mathrm{CCl}_{1}$. Preliminary data in our laboratory have shown that promethazine was less effective as a protective agent if the body temperature of the rat was maintained, indicating that at least a fraction of the protection afforded results from a change in body temperature. Slater et al. ${ }^{3}$ also observed that phenobarbitone and cysteamine had no significant effect on the development of necrosis, yet prevented nucleotide decrease. It would appear, from our observations and those of Larson and $\mathrm{Plaa}^{8}{ }^{8}$ that all protective agents should be screened for a hypothermic effect, with or without the necrogenic agent.

Acknowledgements-The authors wish to acknowledge the excellent technical assistance of Mr. Lawrence A. Carr and to thank Dr. Murray Abell of the Department of Pathology for his advice and help with the histologic aspects of the study.
Department of Pharmacology,
University of Michigan,
Ann Arbor, Mich., U.S.A.
J. W. GiBB*
T. M. BRODY $\dagger$
* Present address: Laboratory of Clinical Biochemistry, National Heart Institute, National In- stitutes of Health, Bethesda, Md., U.S.A.
$\dagger$ Present address: Department of Pharmacology, Michigan State University, East Lansing, Mich., U.S.A.

\section{REFERENCES}

1. G. S. Christie and J. D. Judah, Proc. R. Soc. B 142, 241 (1954).

2. M. U. Dianzant, Biochim. biophys. Acta 17, 391 (1955).

3. D. N. Calvert and T. M. Brody, J. Pharmac. exp. Ther. 124, 273 (1958).

4. C. H. Gallagher and R. A. Simmonds, Nature, Lond. 184, 1407 (1959).

5. C. H. GallaGHeR, Aust. J. exp. Biol. med. Sci. 38, 251 (1960).

6. C. H. Gallagher, Aust. J. agric. Res. 11, 1009 (1960).

7. N. O. Kaplan, A. Goldin, S. R. Humphreys, M. M. Ciotti and F. E. Stolzenbach, J. biol. Chem. 219, 287 (1956).

8. R. E. Larson and G. L. PlaA, J. Pharmac. exp. Ther. 147, 103 (1965).

9. A. W. Lindall, JR. and A. LAZARow, Metabolism 13, 259 (1964).

10. T. M. Brody and J. A. Bain, Proc. Soc. exp. Biol. Med. 77, 50 (1951).

11. A. G. Gornall, C. J. BardawiLl and M. M. David, J. biol. Chem. 177, 751 (1949).

12. T. F. Slater, U. D. Straüli and B. C. Sawyer, Biochem. J. 93, 260 (1964).

13. T. F. Slater, B. C. SAWyer and U. D. STrauli, Biochem. Pharmac. 15, 1273 (1966). 